Journal of Engineering and Applied Sciences 14 (19): 7254-7262, 2019

ISSN: 1816-949X

(C) Medwell Journals, 2019

\title{
Novel BS_SM Nonlinear Control Structure for Field Oriented Control SPIM Drive
}

\author{
${ }^{1}$ Ngoc Thuy Pham and ${ }^{2}$ Khuong Huu Nguyen \\ ${ }^{1}$ Department of Electrical Engineering Technology, Industrial University of Ho Chi Minh City, \\ Ho Chi Minh, +84, Vietnam \\ ${ }^{2}$ Department of TE and Electrical Engineering, Ho Chi Minh City University of Transportirst, \\ Ho Chi Minh, +84, Vietnam
}

\begin{abstract}
This study presents a novel structure of the Backstepping-Sliding mode nonlinear control (BS_SM) of the Six Phase Induction Motor (SPIM). The control design is based on combination SM and BS techniques to improve its performance and robustness, enables very good static and dynamic performance of SPIM drive system, perfect tuning of the speed reference values, fast response of the motor current and torque, high accuracy of speed regulation and robust for the disturbances of the load, the speed variations. The simulation results confirmed the good dynamics and robustness of the proposed control algorithm based on the BS_SM technique.
\end{abstract}

Key words: Six phase induction motor, backstepping control, sliding mode, high accuracy, disturbances, robustness

\section{INTRODUCTION}

In recent decades, the multiphase motor drives are widely used in much applications due to their inherent features such as higher torque density, greater efficiency, reduced torque pulsations, fault tolerance and reduction in the required rating per inverter leg (Levi, 2008). Especially, these drives are often considered in some applications such as locomotive traction, electrical ship propulsion, in high power applications such as automotive, aerospace, military and nuclear (Finch and Giaouris, 2008). With its reliable working characteristics and high failure tolerance now a days, these motors are even considered in the small power applications requiring high reliability and fault tolerance where are expected that the loss of one or more phases the machine still can provide a significant electromagnetic torque to continue operating the system. Among the many types of multiphase motors, SPIM is one of the most widely used multiphase motors.

As the three phase induction motor when uncertainties and disturbances are appreciable, traditional control techniques using PID control for SPIM drives are not able to guarantee optimal performance or can require a considerably time consuming and plant dependent design stage. Therefore, to overcome these drawbacks the nonlinear control techniques have been followed such as for instance, linear output feedback control (Alonge et al., 2015; Abbas et al., 2016), Sliding Mode (SM) (Orlowska-Kowalska et al., 2009; Bartolini et al., 2007), Backstepping control (BS) (Tan et al., 2003; Jovanovic and Bamieh, 2004; Zaafouri et al., 2016; Traore et al., 2010; Morawiec, 2014), Fuzzy Logic (FL) control (Padmanaban et al., 2016; Masumpoor et al., 2015) Neural Networks (NN) control (Fu and Li, 2015; Uddin et al., 2013; Saghafinia et al., 2013), predictive control (Liu et al., 2019), Hamiltonian control (Cecati, 2000; Yu et al., 2006a, b; Cheng and Jiao, 2013; Schaft, 1999; Ortega et al., 2002). In the proposed technics, the $\mathrm{BSC}$ design techniques have received great attention due to its systematic and recursive design methodology for nonlinear feedback control. The BSC design can be used to force a nonlinear system to behave like a linear system in a new set of coordinates. The major advantages are that it has the flexibility to avoid cancelations of useful nonlinearities and pursues the objectives of stabilization and tracking. However, the detailed and accurate informations about system dynamics are required when designing traditional BSC. To overcome this drawback many strategies have been proposed, Lee et al. (2006) proposed a new BS control scheme using a dynamical induction motor model based on the tranditional BS control with the unknown of the damping coefficient, the motor inertia, the load torque and the uncertainty of the machine parameters. The tests carried out without

Corresponding Author: Ngoc Thuy Pham, Department of Electrical Engineering Technology, Industrial University of Ho Chi Minh City, Ho Chi Minh, +84, Vietnam 
applying a load torque. However, the speed ripple and the performance of the tracking the reference speed is not good and it also does not guarantee a total rejection of the load torque disturbance. By Mehazzem et al. (2011) and Traore et al. (2010), an integral version of the control and an adaptive observer using the backstepping technique was proposed. The results show the good performance of the control law and the observer but it may be noted that the problem with this method is the complexity of solving differential equations which require more computing time for processor, since, the model will be increased by two states. Zaafouri et al. (2016) proposed a BS design method for both the control and observer by adding the integral error tracking component to increase the stability of the transmission system, this method for good dynamic response, precise controls. However, the torque ripple is recorded as quite large, the performance at low speed range and regenerating modes not reported by Zaafouri et al. (2016). From the above analysis it is easy to see that the BS control which represents a precise model based control method was difficult to obtain satisfactory control perforance when using independently, especially, in the cases applyed to control the nonlinear systems. Therefore, the combination of $\mathrm{BSC}$ and different robust adaptive control has been received more attentions (Liu et al., 2016a-c; Su et al., 2017; Chen et al., 2014; Sun et al., 2016; Yu et al., 2018; Li et al., 2016). Such as sliding mode control (Liu et al., 2016a-c, 2019; Su et al., 2017), neuron network (Chen et al., 2014; Sun et al., 2016; Yu et al., 2018), Fuzzy Logic System (FLS) (Li et al., 2016; Yuet al., 2015). In this study, the researcher proposes a new combined control structure: the BS controller is applied in outter speed closed loop control. In this proposed BS-based controller design, the integral error tracking component added to improve its sustainability. Due to the fact that SM control can effectively compensate for load disturbance, so, the proposed method use SM in inner current control closed loop is more robust than the conventional adaptive backstepping control used in inner current closed loop control (Zaafouri et al., 2016). This novel BS_SM nonlinear combination structure ensure stability, robustness and fast error dynamics for SPIM drives. The effectiveness of this proposed control structure is verified by simulation using MATLAB/Simulink.

Model of SPIM: The system under study consists of an SPIM fed by a six-phase Voltage Source Inverter (VSI) and a DC link. A detailed scheme of the drive is provided in Fig. 1. By applying the Vector Space Decomposition (VSD) technique introduced by Liu et al. (2019), the

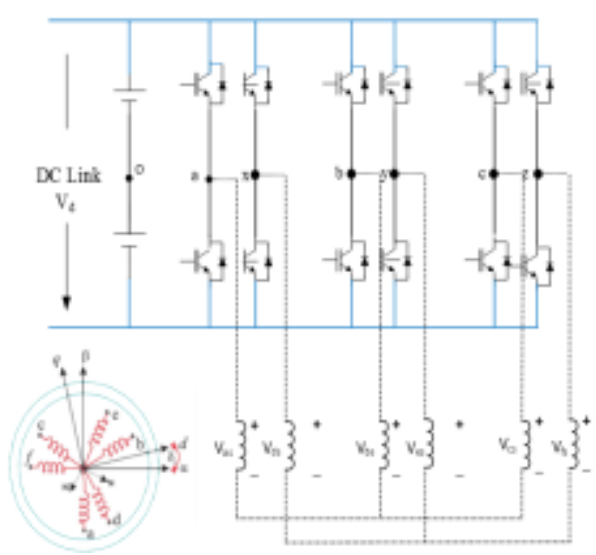

Fig. 1: A general scheme of an SPIM drive

original six-dimensional space of the machine is transformed into three two-dimensional orthogonal subspaces in the stationary reference frame (D-Q), (x-y) and (zl-z2). This transformation is obtained by means of $6 \times 6$ transformation matrix:

$$
\mathrm{T}_{6}=\frac{1}{\sqrt{3}}\left[\begin{array}{cccccc}
1 & \frac{\sqrt{3}}{2} & -\frac{1}{2} & -\frac{\sqrt{3}}{2} & -\frac{1}{2} & 0 \\
0 & \frac{1}{2} & \frac{\sqrt{3}}{2} & \frac{1}{2} & -\frac{\sqrt{3}}{2} & -1 \\
1 & -\frac{\sqrt{3}}{2} & -\frac{1}{2} & \frac{\sqrt{3}}{2} & -\frac{1}{2} & 0 \\
0 & \frac{1}{2} & -\frac{\sqrt{3}}{2} & \frac{1}{2} & \frac{\sqrt{3}}{2} & -1 \\
1 & 0 & 1 & 0 & 1 & 0 \\
0 & 1 & 0 & 1 & 0 & 1
\end{array}\right]
$$

In order to develop SPIM Model for control purposes, some basic assumptions should be made. Hence, the windings are assumed to be sinusoidally distributed, the magnetic saturation, the mutual leakage inductances and the core losses are neglected. The electrical matrix equations in the stationary reference frame for the stator and the rotor may be written as:

$$
\begin{aligned}
& {\left[\mathrm{V}_{\mathrm{s}}\right]=\left[\mathrm{R}_{\mathrm{s}}\right]\left[\mathrm{I}_{\mathrm{s}}\right]+\mathrm{P}\left(\left[\mathrm{L}_{\mathrm{s}}\right]\left[\mathrm{I}_{\mathrm{s}}\right]+\left[\mathrm{L}_{\mathrm{m}}\right]\left[\mathrm{I}_{\mathrm{r}}\right]\right)} \\
& 0=\left[\mathrm{R}_{\mathrm{r}}\right]\left[\mathrm{I}_{\mathrm{r}}\right]+\mathrm{P}\left(\left[\mathrm{L}_{\mathrm{r}}\right]\left[\mathrm{I}_{\mathrm{r}}\right]+\left[\mathrm{L}_{\mathrm{m}}\right]\left[\mathrm{I}_{\mathrm{s}}\right]\right)
\end{aligned}
$$

Where:

$$
\begin{array}{ll}
{[\mathrm{V}]} & =\text { Voltage vector } \\
{[\mathrm{I}]} & =\text { Current vector } \\
{[\mathrm{R}]} & =\text { Resistant vector } \\
{[\mathrm{L}] \text { and }\left[\mathrm{L}_{\mathrm{m}}\right]} & =\text { Self and mutual inductance vectors } \\
\mathrm{P} & =\text { The differential operator }
\end{array}
$$

where, subscript $\mathrm{r}$ and $\mathrm{s}$ related to the rotor and stator, respectively. 
Since, the rotor is squirrel cage, $\left[\mathrm{V}_{\mathrm{r}}\right]$ is equal to zero. The electromechanical energy conversion only takes place in the DQ subsystem:

$$
\mathrm{T}_{\mathrm{dq}}=\left[\begin{array}{cc}
\cos \left(\delta_{\mathrm{r}}\right) & -\sin \left(\delta_{\mathrm{r}}\right) \\
\sin \left(\delta_{\mathrm{r}}\right) & \cos \left(\delta_{\mathrm{r}}\right)
\end{array}\right]
$$

where, $\delta_{\mathrm{r}}$ is the rotor angular position referred to the stator as shown in Fig. 1. As these equations implies, the electromechanical conversion, only takes place in the $\mathrm{D}-\mathrm{Q}$ subspace and the other subspaces just produce losses. Therefore, the control is based on determining the applied voltage in the $D Q$ reference frame. With this transformation, the 6 PIM control technique is similar to the classical three phase IM FOC. The control for the motor in the stationary reference frame is difficult, even for a three phase IM, so, the transformation of SPIM model in a dq rotating reference frame to obtain currents with dc components (Levi, 2008) is necessary, a transformation matrix must be used to represent the stationary reference fame (DQ) in the dynamic reference $(d-q)$. This matrix is given:

$$
\left[\begin{array}{c}
\mathrm{V}_{\mathrm{sD}} \\
\mathrm{V}_{\mathrm{sQ}} \\
0 \\
0
\end{array}\right]=\left[\begin{array}{cccc}
\mathrm{R}_{\mathrm{s}}+\mathrm{PL}_{\mathrm{s}} & 0 & \mathrm{PL}_{\mathrm{m}} & 0 \\
0 & \mathrm{R}_{\mathrm{s}}+\mathrm{PL}_{\mathrm{s}} & 0 & \mathrm{PL}_{\mathrm{m}} \\
\mathrm{PL}_{\mathrm{m}} & \omega_{\mathrm{r}} \mathrm{L}_{\mathrm{m}} & \mathrm{R}_{\mathrm{r}}+\mathrm{PL}_{\mathrm{r}} & \omega_{\mathrm{r}} \mathrm{L}_{\mathrm{m}} \\
-\omega_{\mathrm{r}} \mathrm{L}_{\mathrm{m}} & \mathrm{PL}_{\mathrm{m}} & -\omega_{\mathrm{r}} \mathrm{L}_{\mathrm{m}} & \mathrm{R}_{\mathrm{r}}+\mathrm{PL}_{\mathrm{r}}
\end{array}\right]\left[\begin{array}{c}
\mathrm{I}_{\mathrm{s} \alpha} \\
\mathrm{I}_{\mathrm{s} \beta} \\
\mathrm{I}_{\mathrm{r} \alpha} \\
\mathrm{I}_{\mathrm{r} \beta}
\end{array}\right]
$$

The Field Oriented Control (FOC) is the most used strategy in the industrial field. Its objective is to improve the static and dynamic behavior of asynchronous machine unlike the scalar control. It allows decoupling the electromagnetic quantities in order to make the control similar to DC machine. The principle of the FOC is to align the $\mathrm{d}$ axis of the rotating frame $(\mathrm{Dq}(\mathrm{dq})$ ) with the desired flux as shown in Fig. 1. Therefore, the flux will be controlled by the direct component of the stator current (isd) and the torque by the quadratic component (isq). In this case we obtain:

$$
\psi_{\mathrm{rq}}=0 ; \psi_{\mathrm{rd}}=\psi_{\mathrm{rd}}
$$

Using Eq. 1 and 4, the new model motor dynamics is described by the following space vector differential Eq. 5:

$$
\left\{\begin{array}{l}
\frac{\mathrm{d} \omega}{\mathrm{dt}}=\frac{3}{2} \mathrm{n}_{\mathrm{p}} \frac{\delta \sigma \mathrm{L}_{\mathrm{s}}}{\mathrm{J}}\left(\psi_{\mathrm{rd}} \mathrm{i}_{\mathrm{sQ}}\right)-\frac{\mathrm{T}_{\mathrm{L}}}{\mathrm{J}}-\mathrm{B} \omega \\
\frac{\mathrm{d} \psi_{\mathrm{rd}}}{\mathrm{dt}}=\frac{\mathrm{L}_{\mathrm{m}}}{\tau_{\mathrm{r}}} \mathrm{i}_{\mathrm{sD}}-\frac{1}{\tau_{\mathrm{r}}} \psi_{\mathrm{rd}} \\
\mathrm{L}_{\mathrm{s}} \frac{\mathrm{di}_{\mathrm{sD}}}{\mathrm{dt}}=-\mathrm{ai}_{\mathrm{sD}}+\mathrm{L}_{\mathrm{s}} \omega_{\mathrm{s}} \mathrm{i}_{\mathrm{sQ}}+\mathrm{bR}_{\mathrm{r}} \psi_{\mathrm{rd}}+\mathrm{cu}_{\mathrm{sD}} \\
\mathrm{L}_{\mathrm{s}} \frac{\mathrm{di} \mathrm{sQ}_{\mathrm{sQ}}}{\mathrm{dt}}=-\mathrm{ai}_{\mathrm{sQ}}+\mathrm{L}_{\mathrm{s}} \omega_{\mathrm{s}} \mathrm{i}_{\mathrm{sD}}+\mathrm{b}_{\mathrm{r}} \omega_{\mathrm{r}} \psi_{\mathrm{rd}}+\mathrm{cu}_{\mathrm{sQ}}
\end{array}\right.
$$

Where:

$$
\sigma=1-\frac{\mathrm{L}_{\mathrm{m}}^{2}}{\mathrm{~L}_{\mathrm{s}} \mathrm{L}_{\mathrm{r}}} ; \mathrm{a}=\frac{\mathrm{L}_{\mathrm{m}}^{2} \mathrm{R}_{\mathrm{r}}+\mathrm{L}_{\mathrm{r}}^{2} \mathrm{R}_{\mathrm{s}}}{\sigma \mathrm{L}_{\mathrm{r}}^{2}} ; \mathrm{c}=\frac{1}{\sigma} ; \mathrm{b}=\frac{\mathrm{L}_{\mathrm{m}}^{2} \mathrm{R}_{\mathrm{r}}}{\sigma \mathrm{L}_{\mathrm{r}}^{2}}
$$

The new expression of the electromagnetic torque and the slip frequency are given by:

$$
\begin{gathered}
\mathrm{T}_{\mathrm{e}}=\frac{3}{2} \mathrm{n}_{\mathrm{p}} \frac{\mathrm{L}_{\mathrm{m}}}{\mathrm{L}_{\mathrm{r}}} \psi_{\mathrm{r}} \mathrm{i}_{\mathrm{sQ}} \\
\omega_{\mathrm{sl}}=\frac{\mathrm{L}_{\mathrm{m}}}{\mathrm{L}_{\mathrm{r}}} \psi_{\mathrm{r}} \mathrm{i}_{\mathrm{sQ}}
\end{gathered}
$$

\section{MATERIALS AND METHODS}

\section{Control design for the vector control of spim drive using BSC_SM techniques \\ Backstepping design for the outer speed and flux loops:} In this part, a modification on the BSC technique SPIM is proposed for vector control of SPIM drives. As part of the trajectory tracking, the basic idea of the $\mathrm{BSC}$ is to make the system equivalent to a cascade first order subsystems, giving it strength qualities and overall stability of the asymptotic tracking error. The stability and performance of the systems is studied using the Lyapunov theory. BSC technique is a systematic and recursive method for synthesizing nonlinear control laws. So, a virtual command, that will been generated to ensure the convergence of the systems to their equilibrium states. It allows the synthesis of robust control law despite different types of disturbances and parametric uncertainties [20, TLTK]. In this proposal, the robustness of this scheme is improved by introducing integral terms of the tracking errors in the control design. The following tracking errors are defined:

$$
\begin{aligned}
& \varepsilon_{\omega}=\omega^{*}-\omega+\mathrm{k}_{\omega}^{\prime} \int_{0}^{\mathrm{t}}\left(\omega^{*}-\omega\right) \mathrm{dt} \\
& \varepsilon_{\psi}=\psi \psi_{\mathrm{rd}}^{*}-\psi_{\mathrm{rd}}+\mathrm{k}_{\psi}^{\prime} \int_{0}^{\mathrm{t}}\left(\psi_{\mathrm{rd}}^{*}-\psi_{\mathrm{rd}}\right) \mathrm{dt}
\end{aligned}
$$

To ensure the stability of the outer loops, the virtual inputs isq and isd are used. The dynamics of the tracking errors are given by:

$$
\begin{aligned}
& \varepsilon_{\omega}=\omega^{*}-\frac{3}{2} \mathrm{n}_{\mathrm{p}} \frac{\delta \sigma \mathrm{L}_{s}}{\mathrm{~J}} \psi_{\mathrm{rd}} \mathrm{i}_{\mathrm{sq}}+\frac{\mathrm{T}_{1}}{\mathrm{~J}}+\mathrm{B} \omega+\mathrm{k}_{\omega}^{\prime}\left(\omega^{*}-\omega\right) \\
& \varepsilon_{\psi}=\psi_{\mathrm{rd}}^{*}-\frac{\mathrm{L}_{\mathrm{m}}}{\tau_{\mathrm{r}}} \mathrm{i}_{\mathrm{sd}}+\frac{1}{\tau_{\mathrm{r}}} \psi_{\mathrm{rd}}+\mathrm{k}_{\psi}^{\prime}\left(\psi_{\mathrm{rd}}^{*}-\psi_{\mathrm{rd}}\right)
\end{aligned}
$$

To design BSC scheme, the Lyapunov function is selected as: 


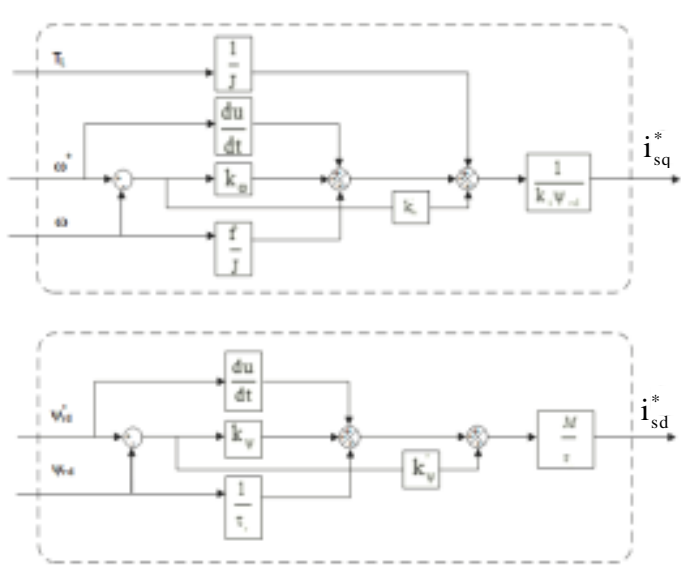

Fig. 2: The virtual inputs $i_{s q}$ and $i_{\text {sd }}$

$$
\mathrm{V}_{(\omega, \psi)}=\frac{1}{2}\left(\varepsilon_{\omega}^{2}+\varepsilon_{\psi}^{2}\right)
$$

its derivative can obtain:

$$
\begin{gathered}
\dot{V}_{(\omega, \psi)}=\varepsilon_{\omega} \varepsilon_{\omega}+\varepsilon_{\psi} \varepsilon_{\psi}=\varepsilon_{\omega}\left[\omega-k_{\mathrm{t}} \psi_{\mathrm{rd}}{ }^{*}{ }^{*}{ }_{\mathrm{sq}}+\frac{\mathrm{T}_{1}}{\mathrm{~J}}+\mathrm{B} \omega+\mathrm{k}_{\omega}^{\prime}\left(\omega^{*}-\omega\right)\right]+ \\
\varepsilon_{\psi_{\mathrm{rd}}}\left\{\psi_{\mathrm{rdd}}^{*}-\frac{\mathrm{L}_{\mathrm{m}}}{\tau_{\mathrm{r}}} \mathrm{i}_{\mathrm{sd}}^{*}+\frac{1}{\tau_{\mathrm{r}}} \psi_{\mathrm{rd}}+\mathrm{k}_{\psi}^{\prime}\left(\psi_{\mathrm{rd}}^{*}-\psi_{\mathrm{rd}}\right)\right\} \\
\mathrm{k}_{\mathrm{t}}=\frac{3}{2} \mathrm{n}_{\mathrm{p}} \frac{\delta \mathrm{s} \mathrm{L}_{\mathrm{s}}}{\mathrm{J}}
\end{gathered}
$$

where, to satisfy $V^{\prime}<0$, the BS control laws are designed as follows:

$$
\begin{aligned}
& \mathrm{i}_{\mathrm{sq}}^{*}=\frac{1}{\mathrm{k}_{\mathrm{t}} \psi_{\mathrm{rd}}}\left\{\mathrm{k}_{\omega} \varepsilon_{\omega}+\omega^{*}+\mathrm{B} \omega+\frac{\mathrm{T}_{1}}{\mathrm{~J}}+\mathrm{k}_{\omega}^{\prime}\left(\omega^{*}-\omega\right)\right\} \\
& \mathrm{i}_{\mathrm{sd}}^{*}=\frac{\tau_{\mathrm{r}}}{\mathrm{L}_{\mathrm{m}}}\left\{\mathrm{k}_{\psi} \varepsilon_{\psi}+\psi_{\mathrm{rd}}^{*}+\frac{1}{\tau_{\mathrm{r}}} \psi_{\mathrm{rd}}+\mathrm{k}_{\psi}^{\prime}\left(\psi_{\mathrm{rd}}^{*}-\psi_{\mathrm{rd}}\right)\right\}
\end{aligned}
$$

where, $k_{\omega}, k_{\Psi}$ are positive constants. Substituting 12 into 11, the derivative of the Lyapunov function can obtain as:

$$
\dot{\mathrm{V}}_{(\omega, \psi)}=-\mathrm{k}_{\omega} \varepsilon_{\omega}^{2}-\mathrm{k}_{\psi} \varepsilon_{\psi}^{2}<0
$$

Equation 12 can be summarized as follows (Fig. 2). In order to realize the tracking of the stator current of induction motors, the SM control is used in the inner loop of SPIM motor.

SMC design for in the inner current loops: In this study, the inner current control objective is to make the measured stator currents is reach the desired currents value is*. SMC is adopted for the currents loop of SPIM drives, a adaptation law for this SMC scheme is derived based on Lyapunov theory to ensure stability and fast error dynamics. Defining the current tracking errors as:

$$
\varepsilon_{\mathrm{s} d \mathrm{~s}}=\mathrm{i}_{\mathrm{sd}}^{*}-\mathrm{i}_{\mathrm{sd}} ; \varepsilon_{\mathrm{ssd}}=i_{\mathrm{sq}}^{*}-i_{\mathrm{sq}}
$$

Consider $s_{1}$ and $s_{2}$ are the two sliding surfaces are defined for $i_{s d}$ and $i_{s q}$, respectively. These sliding surfaces can be described as:

$$
\begin{aligned}
& \mathrm{s}_{1}=\varepsilon_{\mathrm{isd}}+\mathrm{k}_{1} \int_{0}^{\mathrm{t}} \varepsilon_{\mathrm{isd}_{\mathrm{d}}} \mathrm{dt} \\
& \mathrm{s}_{2}=\varepsilon_{\mathrm{iq}}+\mathrm{k}_{2} \int_{0}^{\mathrm{t}} \varepsilon_{\mathrm{isq}_{\mathrm{g}}} \mathrm{dt}
\end{aligned}
$$

where $k_{1}$ and $k_{2}$ are the undetermined coefficient. The time derivative of Lyapunov function yields:

$$
\begin{aligned}
& \mathrm{s}_{1}=\varepsilon_{\mathrm{sid}}+k_{1} \varepsilon_{\mathrm{i}_{\mathrm{sd}}} \\
& \mathrm{s}_{2}=\varepsilon_{\mathrm{iq}}+\mathrm{k}_{2} \varepsilon_{\mathrm{i}_{\mathrm{sq}}}
\end{aligned}
$$

Substituting Eq. 5-17 and combinating to the sliding mode exponential approach law, we get the following Eq. 18 and 19:

$$
\begin{aligned}
& \mathrm{s}_{1}=\varepsilon_{i_{s d}}+k_{1} \varepsilon_{i_{s d}}=i_{s d}^{*}+\frac{1}{L_{s}}\left[a i_{s d}-L_{s} \omega_{s_{s q}}-b R_{r} \psi_{r d}-c_{s d}\right]+ \\
& k_{1} \varepsilon_{i_{s d}}=-\alpha_{1} \operatorname{sign}\left(s_{1}\right)-\beta_{1} s_{1} \\
& \mathrm{~s}_{2}=\varepsilon_{i q}+k_{2} \varepsilon_{i_{s q}}=i_{s q}^{*}+\frac{1}{L_{s}}\left[a_{i_{s q}}-L_{s} \omega_{s} i_{s d}-b_{r} \omega_{r} \psi_{r d}-c_{s D}\right]+ \\
& k_{2} \varepsilon_{i_{s q}}=-\alpha_{2} \operatorname{sign}\left(s_{2}\right)-\beta_{2} s_{2}
\end{aligned}
$$

where, $\alpha_{1}, \alpha_{2}, \beta_{1}, \beta_{2}$ are positive constants and the sign function is defined as:

$$
\operatorname{sign}\left(\mathrm{s}_{\mathrm{i}}\right)=\left\{\begin{array}{lll}
-1 & \text { for } & \mathrm{s}_{\mathrm{i}}<0 \\
+1 & \text { for } & \mathrm{s}_{\mathrm{i}}>0
\end{array}\right\} ; \mathrm{i}=1,2
$$

The SM control law can be found using Lyapunov theory and defining the Lyapunov function candidate:

$$
\mathrm{V}=\frac{1}{2}\left(\mathrm{~s}_{1}^{2}+\mathrm{s}_{2}^{2}\right)
$$

The time derivative of Lyapunov function (20) can be calculated as: 


$$
\mathrm{V}=\mathrm{s}_{1} \mathrm{~s}_{1}+\mathrm{s}_{2} \mathrm{~s}_{2}
$$

According to Lyapunov theory, if the function $\mathrm{v}$ is negative definite, this will ensure that the state trajectory will be driven and attracted toward the sliding surface $\mathrm{s}$ and once reached, it will remain sliding on it until the origin is reached asymptotically. Combining Eq. 14-21 and the condition to satisfy the stability of the inner loops, the reference voltage of the stator $\mathrm{d}$ and the $\mathrm{q}$ axis are chossed as follows:

$$
\begin{gathered}
\mathrm{u}_{\mathrm{sd}}=\frac{\mathrm{L}_{\mathrm{s}}}{\mathrm{c}}\left(\begin{array}{l}
\alpha_{1} \operatorname{sign}\left(\mathrm{s}_{1}\right)+\beta_{1} \mathrm{~s}_{1}+\mathrm{i}_{\mathrm{sd}}^{*}+ \\
\frac{1}{\mathrm{~L}_{\mathrm{s}}}\left(\mathrm{ai}_{\mathrm{sd}}-\mathrm{L}_{\mathrm{s}} \omega_{\mathrm{s}} \mathrm{i}_{\mathrm{sq}}-\mathrm{bR}_{\mathrm{r}} \psi_{\mathrm{rd}}\right)+\mathrm{k}_{1} \varepsilon_{\mathrm{i}_{\mathrm{sd}}}
\end{array}\right) \\
\mathrm{u}_{\mathrm{sq}}=\frac{\mathrm{L}_{\mathrm{s}}}{\mathrm{c}}\left(\begin{array}{l}
\alpha_{2} \operatorname{sign}\left(\mathrm{s}_{2}\right)+\beta_{2} \mathrm{~s}_{2}+\mathrm{i}_{\mathrm{sq}}^{*}+ \\
\frac{1}{\mathrm{~L}_{\mathrm{s}}}\left(\mathrm{ai}_{\mathrm{sq}}+\mathrm{L}_{\mathrm{s}} \omega_{\mathrm{s}} \mathrm{i}_{\mathrm{sd}}+\mathrm{b}_{\mathrm{r}} \omega_{\mathrm{r}} \psi_{\mathrm{rq}}\right)+\mathrm{k}_{2} \varepsilon_{\mathrm{i}_{\mathrm{sq}}}
\end{array}\right)
\end{gathered}
$$

This ensure that:

$$
\mathrm{V}=-\alpha_{1} \operatorname{sgn}\left(\mathrm{s}_{1}\right) \mathrm{s}_{1}-\beta_{1} \mathrm{~s}_{1}^{2}-\alpha_{2} \operatorname{sgn}\left(\mathrm{s}_{2}\right) \mathrm{s}_{2}-\beta_{2} \mathrm{~s}_{2}^{2}<0
$$

\section{RESULTS AND DISCUSSION}

The vector contronl for IFOC induction motor drive system is simulated by using MATLAB Software. The block diagram of system is shown in Fig. 3. The proposed BS_SM control is compared to the classical control using a PI controller, to show the effectiveness of the proposed algorithm. The results analysis shows the characteristic robustness of the BS_SM control to disturbances of the load, the speed variations.

SPIM parameters: The $1 \mathrm{Hp}, 220 \mathrm{~V}, 50 \mathrm{~Hz}, 4$ pole, $1450 \mathrm{rpm} . \mathrm{Rs}=10.1 \Omega, \mathrm{Rr}=9.8546 \Omega, \mathrm{Ls}=0.833457 \mathrm{H}$, $\mathrm{Lr}=0.830811 \mathrm{H}, \mathrm{m}=0.783106 \mathrm{H}, \mathrm{Ji}=0.0088 \mathrm{~kg} / \mathrm{m}^{2}$. Rs is nominal value of stator resistance.

Dynamic performance of SPIM on speed reversal: The speed, torque and current stator responses are shown in Fig. 4. The speed reference in this case is set up speed reversal from 1000 to $-1000 \mathrm{rpm}$ at rated load for PI and BS_SM controllers, respectively. Initially, motor is accelerated in both the cases is is easy to see that BS_SM controller can provide stability and fast dynamic responses, speed transient time from $0-1000 \mathrm{rpm}$ at in the case of PI controller is 0.17 and $0.13 \mathrm{sec}$ in the case of BS_SM controller as shown in Fig. 5, respectively. When motor runs at steady state at $1000 \mathrm{rpm}$, a step speed command of $-1000 \mathrm{rpm}$ is applied at $\mathrm{t}=1 \mathrm{sec}$. As soon as $-1000 \mathrm{rpm}$ is applied, negative torque is developed on the shaft of the rotor, consequently motor starts decelerating achieving zero speed and then starts accelerating in reverse direction and finally, get in settled down at $-1000 \mathrm{rpm}$. Total time taken speed reversal of the SPIM drive using PI controller is 0.15 and $0.1 \mathrm{sec}$ using BS_SM controller, respectively. Comparison the response time of load torque dynamics of BS_SM and PI techniques for the FOC SPIM drive its speed reverse from 1000 to $-1000 \mathrm{rpm}$ is $0.185 \mathrm{sec}$ in case of PI controller and $0.12 \mathrm{sec}$ in case of BS_SM cotroller.

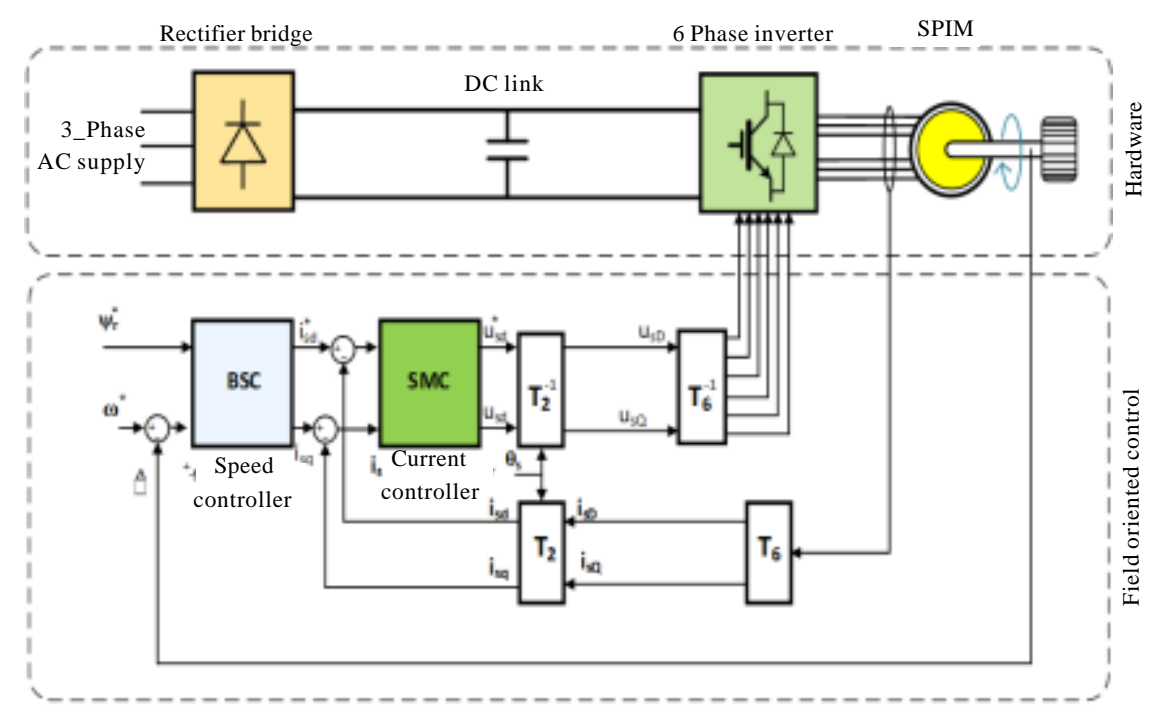

Fig. 3: The vector control of SPIM drive using BS_SM control 

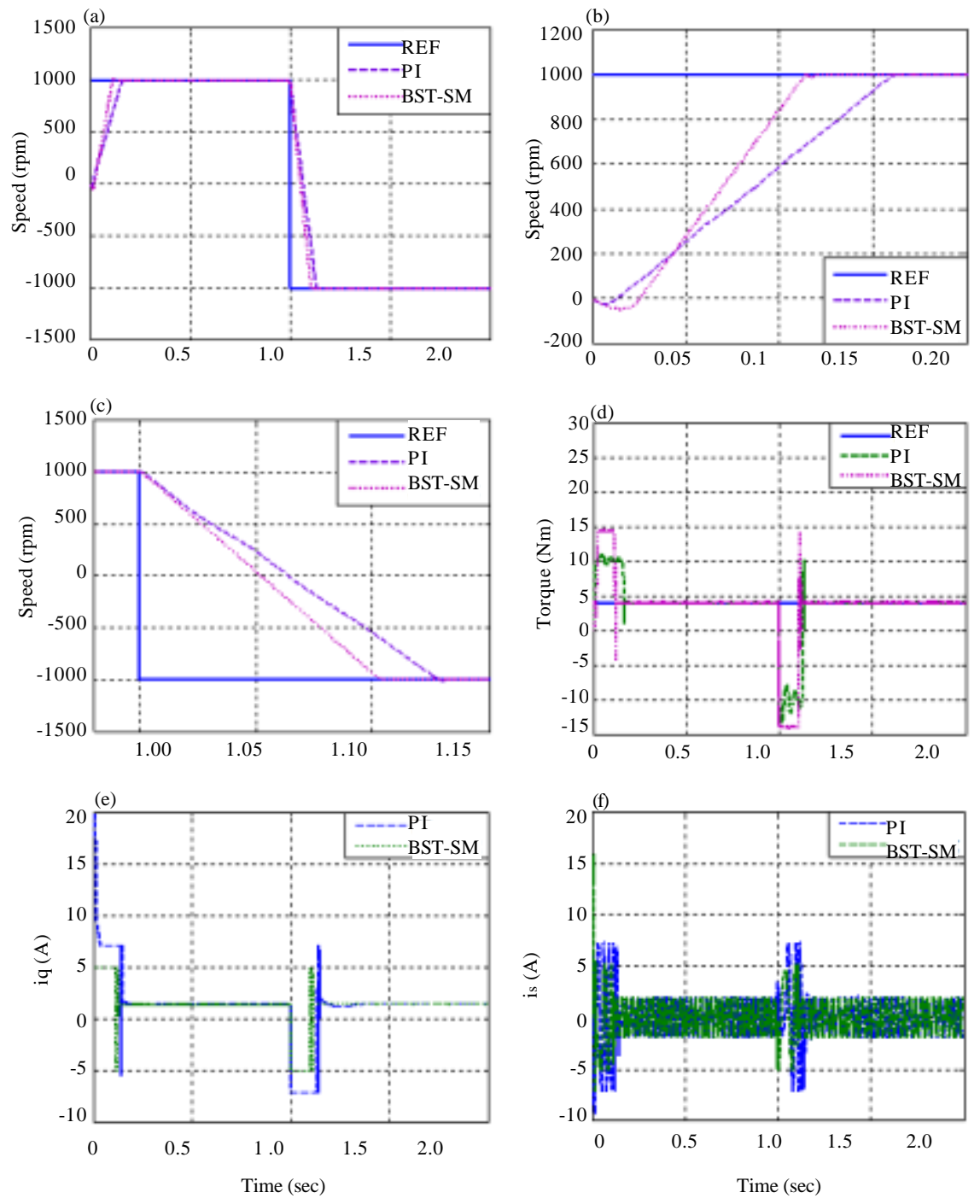

Fig. 4: a-f) The dynamics preformance of SPIM drive with PI and BS_SM controller

From the simulation results show that the dynamic performance of the vector control of SPIM drive are using BS SM very good, the real speed follows the reference speed, the speed tracking efficiency is high, fast dynamic responses. Compare with the results obtained using PI controller, we can see that the proposed SPIM vector control strategy using BS_SM controller give better dynamic performance for using conventional PI controller. In this proposed vector control, tracking performance, overshoot, transition time are better. Also, proposed controller has the fast torque response and low torque ripple.

Performance of IM on step load disturbance: The SPIM is started without load torque until the sudden rated load is supplied at $\mathrm{t}=1 \mathrm{sec}$. The reference spee $\mathrm{d}$ is increased from $1000-1400 \mathrm{rpm}$ at $\mathrm{t}=0.5 \mathrm{sec}$ and decreased from $1400-800 \mathrm{rpm}$ at $\mathrm{t}=1.5 \mathrm{sec}$. The responses of SPIM drive are shown in Fig. 5. In the PI control, it reached $1000 \mathrm{rpm}$ in 0.1 and $0.75 \mathrm{sec}$ with BS SM control. The transition time of BST_SM controller is shorter than PI controller for all reference speed. In the PI control study, the speed dips to $1372 \mathrm{rpm}$ and takes $0.35 \mathrm{sec}$ to recover the speed to reference value. In the BST_SM, the speed dips to 1390 $\mathrm{rpm}$ and takes $0.21 \mathrm{sec}$ to recover the speed to refernce value. Figure 5 shows that BS_SM controller has a shorter rise time, settling time and recovery time than PI controller. Also, proposed controller has the fast torque response and low torque ripple. The simulation results show that the characteristic robustness of the BST_SM control to disturbances of the load and the speed variations is better than conventional the PI control. 

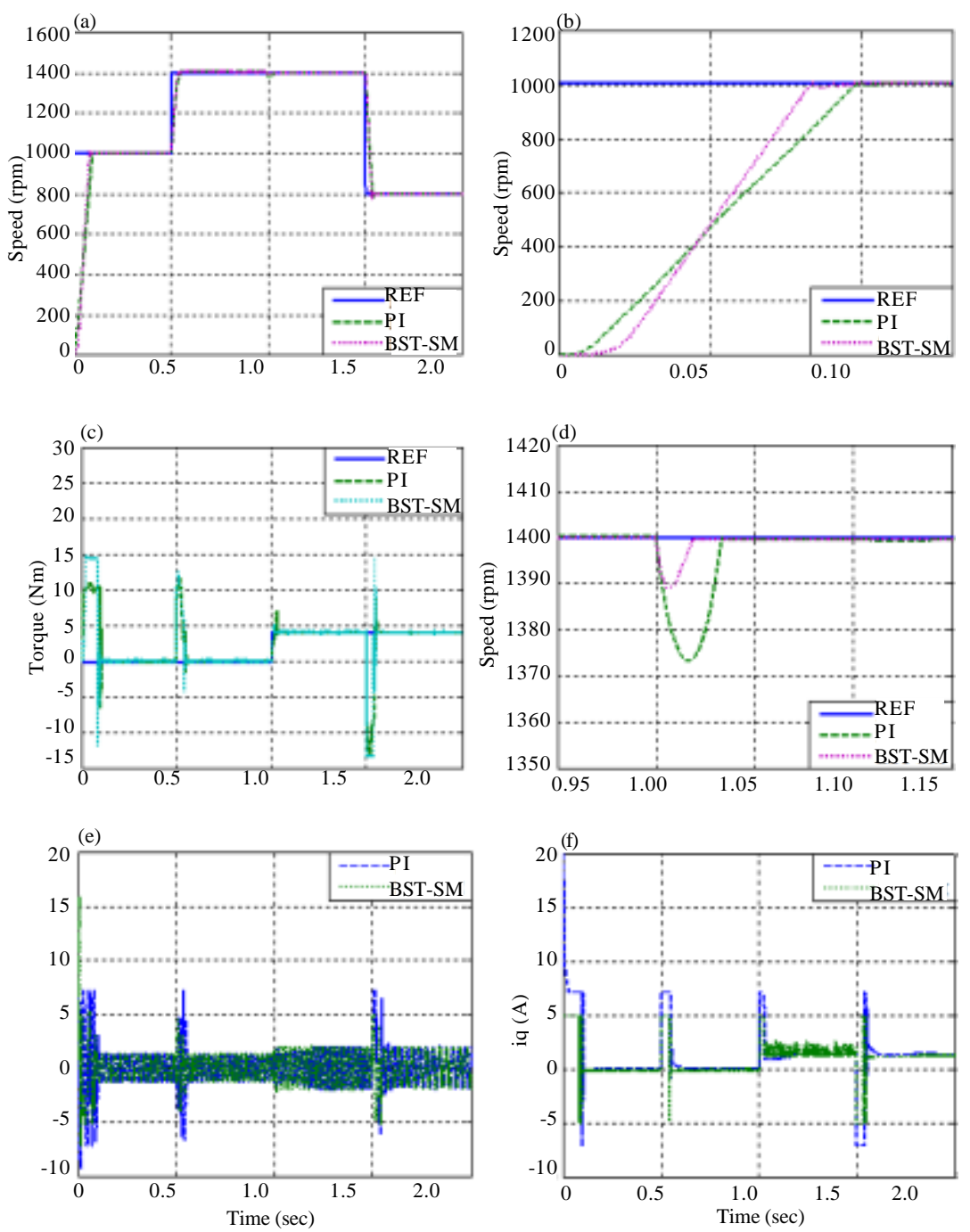

Fig. 5: a-f) Performance of SPIM drive on the load disturbance

\section{CONCLUSION}

This study proposes a novel control structure combing the adaptive Backstepping (BS) and Sliding Mode (SM) control technicques to improve the performance and enhance the robustness of the vector control of Six Phase Induction Motor (SPIM) drives. The BS controller is proposed in outter speed closed loop control, the BS-based controller design, the integral error tracking component added to improve its sustainability. The SM control is proposed in inner current closed loop control to can effectively compensate for load disturbance in the system, so, the proposed method is more robust, stability and faster dynamics response. The proposed vector speed control scheme is validated through
MATLAB-Simulink. The simulation results confirm the good dynamics and robustness of the proposed control algorithm based on BS_SM technique.

\section{REFERENCES}

Abbas, H.A., M. Belkheiri and B. Zegnini, 2016. Feedback linearisation control of an induction machine augmented by single-hidden layer neural networks. Intl. J. Contr., 89: 140-155.

Alonge, F., M. Cirrincione, M. Pucci and A. Sferlazza, 2015. Input-output feedback linearization control with on-line MRAS-based inductor resistance estimation of linear induction motors including the dynamic end effects. IEEE. Trans. Ind. Appl., 52: 254-266. 
Bartolini, G., E. Punta and T. Zolezzi, 2007. Approximability properties for second-order sliding mode control systems. IEEE. Trans. Autom. Contr., 52: 1813-1825.

Cecati, C., 2000. Position control of the induction motor using a passivity-based controller. IEEE. Trans. Ind. Appl., 36: 1277-1284.

Chen, W., S.S. Ge, J. Wu and M. Gong, 2014. Globally stable adaptive backstepping neural network control for uncertain strict-feedback systems with tracking accuracy known a priori. IEEE. Trans. Neural Netw. Learn. Syst., 26: 1842-1854.

Cheng, Z. and L. Jiao, 2013. Hamiltonian modeling and passivity-based control of permanent magnet linear synchronous motor. J. Comput., 8: 501-508.

Finch, J.W. and D. Giaouris, 2008. Controlled AC electrical drives. IEEE. Trans. Ind. Electron., 55: 481-491.

$\mathrm{Fu}, \mathrm{X}$. and $\mathrm{S}$. Li, 2015. A novel neural network vector control technique for induction motor drive. IEEE. Trans. Energy Convers., 30: 1428-1437.

Jovanovic, M.R. and B. Bamieh, 2004. Architecture induced by distributed backstepping design. Proceedings of the 43rd IEEE International Conference on Decision and Control (CDC) (IEEE Cat. No. 04CH37601) Vol. 4, December 14-17, 2004 , IEEE, Nassau, Bahamas, pp: 3774-3779.

Lee, H.T., L.C. Fu and F.L. Lian, 2006. Sensorless adaptive backstepping speed control of induction motor. Proceedings of the 45th IEEE International Conference on Decision and Control, December 13-15, 2006, IEEE, San Diego, California, USA., pp: $1252-1257$.

Levi, E., 2008. Multiphase electric machines for variable-speed applications. IEEE Trans. Ind. Electr., 55: 1893-1909.

Li, H., L. Wang, H. Du and A. Boulkroune, 2016. Adaptive fuzzy backstepping tracking control for strict-feedback systems with input delay. IEEE. Trans. Fuzzy Syst., 25: 642-652.

Liu, J., S. Vazquez, L. Wu, A. Marquez and H. Gao et al., 2016a. Extended state observer-based sliding-mode control for three-phase power converters. IEEE. Trans. Ind. Electron., 64: 22-31.

Liu, J., W. Luo, X. Yang and L. Wu, 2016c. Robust model-based fault diagnosis for PEM fuel cell air-feed system. IEEE. Trans. Ind. Electron., 63: 3261-3270.

Liu, Y., S. Cheng, B. Ning and Y. Li, 2019. Performance enhancement using durational model predictive control combined with backstepping control and disturbance observer for electrical drives. J. Vibr. Contr., 25: 946-959.
Liu, Z., B. Chen and C. Lin, 2016b. Adaptive neural backstepping for a class of switched nonlinear system without strict-feedback form. IEEE. Trans. Syst. Man Cybern. Syst., 47: 1315-1320.

Masumpoor, S., H. Yaghobi and M.A. Khanesar, 2015. Adaptive sliding-mode type-2 neuro-fuzzy control of an induction motor. Expert Syst. Appl., 42: 6635-6647.

Mehazzem, F., A.L. Nemmour, A. Reama and H. Benalla, 2011. Nonlinear integral backstepping control for induction motors. Proceedings of the International Aegean Joint Conference on Electrical Machines and Power Electronics and Electromotion, September 8-10, 2011, IEEE, Istanbul, Turkey, pp: 331-336.

Morawiec, M., 2014. Z-type observer backstepping for induction machines. IEEE. Trans. Ind. Electron., 62: 2090-2102.

Orlowska-Kowalska, T., M. Dybkowski and K. Szabat, 2009. Adaptive sliding-mode neuro-fuzzy control of the two-mass induction motor drive without mechanical sensors. IEEE. Trans. Ind. Electron., 57: 553-564.

Ortega, R., A.V.D. Schaft, B. Maschke and G. Escobar, 2002. Interconnection and damping assignment passivity-based control of port-controlled Hamiltonian systems. Autom., 38: 585-596.

Padmanaban, S., F.D. Л, F. Blaabjerg, N. Mir-Nasiri and A.H. Ertas, 2016. Numerical implementation of wavelet and fuzzy transform IFOC for three-phase induction motor. Eng. Sci. Technol. Intl. J., 19: 96-100.

Saghafinia, A., H.W. Ping and M.N. Uddin, 2013. Sensored field oriented control of a robust induction motor drive using a novel boundary layer fuzzy controller. Sens., 13: 17025-17056.

Schaft, A.J.V.D., 1999. L2-Gain and Passivity Techniques in Nonlinear Control. 2nd Edn., Springer, London, UK., ISBN:9781852330736, Pages: 248.

$\mathrm{Su}$, Q., W. Quan, G. Cai and J. Li, 2017. Improved adaptive backstepping sliding mode control for generator steam valves of non-linear power systems. IET. Contr. Theory Appl., 11: 1414-1419.

Sun, Y., B. Chen, C. Lin, H. Wang and S. Zhou, 2016. Adaptive neural control for a class of stochastic nonlinear systems by backstepping approach. Inf. Sci., 369: 748-764.

Tan, Y., J. Chang and H. Tan, 2003. Adaptive backstepping control and friction compensation for AC servo with inertia and load uncertainties. IEEE. Trans. Ind. Electron., 50: 944-952.

Traore, D., J.D. Leon and A. Glumineau, 2010. Sensorless induction motor adaptive observer-backstepping controller: Experimental robustness tests on low frequencies benchmark. IET. Contr. Theory Appl., 4: 1989-2002. 
Uddin, M.N., Z.R. Huang and A.S. Hossain, 2013. Development and implementation of a simplified self-tuned neuro-fuzzy-based IM drive. IEEE. Trans. Ind. Appl., 50: 51-59.

Yu, H., K. Zhao, H. Wang and L. Guo, 2006b. Energy shaping control of PM synchronous motor based on load torque observer. Syst. Eng. Electron., 28: 1740-1742.

Yu, H.S., K.Y. Zhao, L. Guo and H.L. Wang, 2006a. Maximum torque per ampere control of PMSM based on port-controlled hamiltonian theory. Proc. CSEE., 26: 82-87.
Yu, J., B. Chen, H. Yu, C. Lin and L. Zhao, 2018. Neural networks-based command filtering control of nonlinear systems with uncertain disturbance. Inf. Sci., 426: 50-60.

Yu, J., P. Shi, W. Dong and H. Yu, 2015. Observer and command-filter-based adaptive fuzzy output feedback control of uncertain nonlinear systems. IEEE. Trans. Ind. Electron., 62: 5962-5970.

Zaafouri, A., C.B. Regaya, H.B. Azza and A. Chaari, 2016. DSP-based adaptive backstepping using the tracking errors for high-performance sensorless speed control of induction motor drive. ISA. Trans., 60: 333-347. 